4 World Bank. World development indicators database. New York: World Bank, 2004 Barnett T, Barr D, Ivanov A, Slay B. Reversing the epidemic: facts and policy. HIV/AIDS in Eastern Europe and the Commonwealth of Independent States. HIV/AIDS in Eastern Europe and the Commonwealth of Indep

6 Transparency International. Transparency International corruption perceptions index. Berlin: TI, 2004

7 Adeyi O, Chakraborty S, Ghys P, Mikkelsen H. Funding required for the response to HIV/AIDS in Eastern Europe and Central Asia. Mexico City: Futures Group and Instituto Nacional de Salud Publica, World Bank, UNAIDS Secretariat, 2003.
8 United Nations Development Programme. Human development report Unitet: Nulusat libery in (a) http://hdr.undp.org/reports/global/2004/pdf/hdr04_complete.pd accessed 23 June 2005)

9 Ukraine. UNAIDS/WHO epidemiological fact sheets on HIV/AIDS and sexually transmitted infections, 2004 update. www.who.int/GlobalAtlas/ PDFFactory/HIV/EFS_PDFs/EFS2004_UA.pdf (accessed 27 Aug 2004).

10 Barnett T, Whiteside A, Khodakevich L, Kruglov Y, Steshenko V. The HIV/AIDS epidemic in Ukraine: its potential social and economic impact. Soc Sci Med 2000;51: 1387-403.

\title{
Commentary: HIV is not just a transitional problem
}

\author{
Thomas E Novotny
}

The HIV and AIDS epidemic in eastern Europe and central Asia is changing. ${ }^{1-2}$ Despite data limitations, this region shows the fastest growth in HIV in the world. ${ }^{3}$ At the end of 2004, between 920000 and 2.1 million people in the region were living with HIV, compared with about 160000 in 1995. Most countries in the region have low level epidemics, with less than $1 \%$ prevalence among pregnant women and less than $5 \%$ prevalence among high risk groups. The countries most affected are Ukraine, Russia, and the Baltic states, but incidence is also increasing elsewhere. The driving force in most countries has been intravenous drug use, but other contributors include migration, commercial sex work, increasing rates of sexually transmitted infection, widening economic disparities, and multiple high risk behaviours among prison populations.

Rhodes and Simic describe in detail the risk environment that prevails in eastern Europe and the western Balkans. ${ }^{1}$ As national borders have been progressively opened, HIV risks have migrated across them along with people and goods, including illicit drugs. Civil society protections have not kept up with this globalisation, nor have legal frameworks that consider members of vulnerable groups as criminals or social deviants. But people with HIV infection are not deviants: they are predominantly young (more than $80 \%$ of new HIV cases occur in people younger than 30); they may be disenfranchised groups such as the Roma; they may be transport workers with sexually transmitted infection; and they are certainly heterosexual partners of intravenous drug users (the main bridge population).

DeBell and Carter (see p 216) describe how poverty and wealth disparities in Ukraine create fatalism and hopelessness about social risks and the exploding HIV epidemic. ${ }^{2}$ There is a critical lack of investment in health systems and in effective national strategies to control the spread of HIV. Corruption, trafficking, and stigma triangulate to isolate HIV outside the mainstream of health systems, thus assuring that official action will be slow.

\section{Global preventive opportunity}

HIV in eastern Europe and central Asia is now on the agenda for the international health community. The Global Fund to Fight AIDS, Tuberculosis, and Malaria; the World Bank; and European and other bilateral donors have given grants. ${ }^{4}$ It is rare that the international community has the opportunity to prevent an explosive problem, but that opportunity is at hand with HIV in eastern Europe. High level political commitment, attention to economic disparities, support for youth oriented programmes, programmes to reduce harm, and increased responsiveness of transitional health systems are all key components of HIV prevention. Without such bold actions, HIV will become an important and devastating long term problem for transitional health systems.

Competing interests: None declared.

\footnotetext{
1 Rhodes T, Simic M. Transition and the HIV risk environment. BMJ 2005;331:220-3.

DeBell D, Carter R. The impact of transition on public health in Ukraine: A case study of the HIV/AIDS epidemic. BMJ 2005;331:216-9.

3 UNAIDS/WHO. AIDS epidemic update: December 2004. www.unaids.org UNAIDS/WHO. AIDS epidenic

Chapter6_eastern_europe_centralasia_en.pdf.

4 Rosenmöller M, Novotny TE, Godinho J. HIV/AIDS at Europe's eastern edge: Economic and demographic challenges for health systems and disenfranchised populations. EUROHealth (in press).
}

Department of Epidemiology and Biostatistics, Institute for Global Health, University of California, San Francisco, CA, USA Thomas E Novotny director of international programmes tnovotny@ psg.ucsf.edu

\section{Randomised controlled trials for the $B M J$ need to be registered}

If you are the author of a randomised controlled trial that begins enrolment of patients after 1 July 2005 you must register it in a public trials registry, at or before the start of enrolment, for it to be considered for publication in the $B M J$. Trials that began patient enrolment on or before 1 July 2005 must be registered before 13 September 2005 to be considered for publication.

The $B M / \mathrm{s}$ criteria for a suitable public trials registry are that it is free to access, searchable, and identifies trials with a unique number; that registration is free or at minimal cost; that registered information is validated; that registered entry includes details to identify the trial and investigator and includes the status of the trial; and that the research question, methods, intervention, funding, and sponsorship must all be disclosed.

When you submit your paper to the $B M J$ please state the registration number of the trial and the name of the trials registry in the last line of your paper's structured abstract. 